INVESTIGACIÓN

http://doi.org/10.15198/seeci.2019.49.39-57

Recibido: 27/08/2018 --- Aceptado: 22/02/2019 --- Publicado: 15/07/2019

\title{
LA AUTORÍA EN EL CINE CLÁSICO DE HOLLYWOOD
}

\section{AUTHORSHIP IN CLASSIC HOLLYWOOD CINEMA}

\author{
(i) 8 Raría Lara1: Universidad Complutense. España. \\ mlara04@ucm.es
}

Antonio Lara2: Universidad Rey Juan Carlos. España. antonio.lara@urjc.es

\section{RESUMEN}

Desde los comienzos del cine, en los que una sola persona se ocupaba prácticamente de todo, la organización de la creación de un film fue evolucionando, y las diversas funciones del proceso fueron aumentando y especializándose progresivamente. La noción de autoría colectiva es un concepto difícil de abordar y de comprender en toda su dimensión. En este artículo se pretende analizarlo, tras estudiar de qué modo la estructura de colaboración en equipo de aquella época influía en sus creadores, y por qué razón se considera que unos son autores, mientras a otros se les niega esa condición. Para examinar a fondo cuál era el sistema de trabajo real de los distintos oficios se han consultado -además de estudios anteriores en libros, revistas y documentales-, las revistas profesionales, buscando entrevistas a directores de fotografía, guionistas, directores, productores... Se ha constatado que hay ciertas figuras clave como el productor, el director de fotografía, el montador o el supervisor de montaje cuyas aportaciones a la autoría han sido ignoradas pensando que su labor se ceñía a responsabilidades meramente técnicas, logísticas o de financiación. En concreto, el caso del productor es especialmente sangrante, pues incluso tiene fama de arruinar el trabajo del resto del equipo para obtener un mayor beneficio económico, cuando lo cierto es que desarrollaban funciones clave, que en la actualidad se atribuyen al director.

PALABRAS CLAVE: cine - clásico - Hollywood - autor - creador - audiovisual película.

\section{ABSTRACT}

From the beginning of the cinema, in which only one person took care of almost everything, the organization of a film progressively evolved, and the different functions in the process got wider and more specialized. The notion of collective

\footnotetext{
1María Lara: Profesora de Comunicación Audiovisual desde 2003, actualmente en la Universidad Complutense. A su vez trabaja como montadora de cine desde 1994.

mlara04@ucm.es

${ }^{2}$ Antonio Lara: Profesor titular en la Universidad Rey Juan Carlos y montador de 16 largometrajes desde 1994, entre los que destaca A/ sur de Granada, de F. Colomo.

antonio.lara@urjc.es
} 
authorship is a difficult concept to approach and understand in all its dimensions. In this article we try to clarify it after analyzing how the structure of team collaboration at that time influenced its creators, and why some can be considered authors while others are denied that status. In order to examine in depth what was the real procedure of the different trades, professional journals have been consulted, looking for interviews with photography directors, writers, directors, producers... in addition to previous studies in books, magazines and documentaries. It is found that there are certain figures that have been unfairly ignored, like the producer, the director of photography, the editor or the supervising editor, because their contribution was not a merely technical or managerial job. The case of the producer is specially discriminatory as it is usually thought they were exclusively focused in the economical aspects of the production, while they assumed key roles now usually part of the directors duties.

KEY WORDS: cinema - classical - Hollywood - author - creator - audiovisual - film.

\section{A AUTORIA NO CINEMA CLÁSSICO DE HOLLYWOOD}

\section{RESUME}

Desde o começo do cinema, em que uma só pessoa se ocupava praticamente de tudo, a organização da criação de um filme foi evolucionando, e as diversas funções do processo foram aumentando e especializando-se progressivamente. A noção de autoria coletiva é um conceito difícil de abordar e de compreender em toda a sua dimensão. Neste artigo pretende-se analisa-lo, depois estudar de que modo a estrutura de colaboração em equipe daquela época influía em seus criadores, e por qual razão se considera que uns são autores, enquanto outros são negadas esta condição. Para examinar a fundo qual era o sistema de trabalho real dos distintos ofícios foram consultados ademais de estudos anteriores em livros, revistas profissionais, buscando entrevistas aos diretores de fotografia, roteiristas, diretores, produtores etc. Foi constatado que há certas figuras chave como o produtor, o diretor de fotografia, o montador ou supervisor de montagem cujas contribuições à autoria foram ignoradas pensando que seu trabalho se ajustava à responsabilidades meramente técnicas, logísticas ou de financiamento. Em concreto, o caso do produtor é especialmente sangrento inclusive tem fama de arruinar o trabalho do resto da equipe para obter um maior benefício econômico, quando o certo é que desenvolviam funções clave, que na atualidade se atribuem ao diretor.

PALAVRAS CHAVE: cinema - clássico - Hollywood - autor - criador - audiovisual filme.

\section{Cómo citar el artículo:}

Lara, M., y Lara, A. (2019). La autoría en el cine clásico de Hollywood. [Authorship in classic Hollywood cinema]. Revista de Comunicación de la SEECI, 49, 39-57. doi: http://doi.org/10.15198/seeci.2019.49.39-57

Recuperado de http://www.seeci.net/revista/index.php/seeci/article/view/553

Revista de Comunicación de la SEECI. 15 julio, 2019 / 15 noviembre, 2019, no 49, 39-57 


\section{INTRODUCCIÓN}

Desde los comienzos del cine, en los que una sola persona se ocupaba prácticamente de todo, la organización de la creación de un film fue evolucionando, y las diversas funciones del proceso fueron aumentando y especializándose progresivamente, surgiendo nuevos puestos, aunque algunos de estos profesionales apenas variaron en sus responsabilidades generales, como se analizará a lo largo del estudio. En un principio, operadores de cámara como el célebre Edwin S. Porter escogían el argumento, dirigían a los participantes en la escena, configuraban la iluminación y los decorados, optaban por un modelo de lentes, un determinado encuadre, el tipo de película virgen... Y posteriormente al rodaje, se ocupaban de revelar el material impresionado y de darle sentido en la sala de montaje.

Sin embargo, este sistema se tornó muy lento a la hora de dar respuesta a las exigencias de los exhibidores, que ya en la primera década del siglo XX, estaban requiriendo a los fabricantes una media de entre veinte y treinta estrenos semanales, según afirmaba Janet Staiger (Bordwell, 1997, p. 133). Y añadía: "La planta Selig es una enorme fábrica de arte donde se producen películas con el mismo nivel de eficiencia organizativa, división del trabajo y manipulación de la materia, que si fueran locomotoras o máquinas de coser". A pesar de que durante esta etapa, directores-productores como D. W. Griffith eran los máximos responsables de las películas, la especialización por departamentos había convertido al cine en un arte colectivo.

Aunque no todas las voces se pronunciaban a favor del dominio hollywoodiense: la célebre expresión "fábrica de sueños", tantas veces nombrada en sentido positivo fue en realidad acuñada por el crítico Ehrengurg en 1931 como denuncia del papel de la industria cinematográfica, responsable de "películas adormecedoras de la conciencia que embrutecían a millones de personas"(Ehrengurg, 2008). Debido a la premura con la que se llevaban a cabo las obras, Jack Warner llegó a decir irónicamente: "No quiero que sea buena, la quiero el martes"(Apple, 2006).

Resulta llamativa la utilización temprana del término "arte" en el artículo citado en Bordwell sobre la planta Selig, porque según Gubern (2016, p. 151), fue el escritor y periodista Ricciotto Canudo quien se atrevió a nombrar al cine como "Séptimo Arte" en su Manifiesto de las siete artes.

Aunque según señala Gutiérrez García, no se reconocerían legislativamente las obras cinematográficas como tales hasta la Conferencia de Bruselas de 1948: "Los términos "obras literarias y artísticas" comprenden todas las producciones de dominio literario, científico y artístico, cualesquiera que sean el modo o la forma de expresión, tales como [...] las obras cinematográficas y las obtenidas por un procedimiento análogo a la cinematografía". (Gutiérrez García, 2018, p. 3).

Las primeras alusiones al invento cinematográfico se recogieron en el Acta de Berlín de 1908. En aquel momento, era considerado únicamente como un medio de "reproducción y representación" y la regulación se centraba en proteger las obras 
preexistentes en las que estaban basadas las películas (Gutiérrez García, 2018, p. 3). En este sentido, se hizo célebre en Hollywood el pleito acerca de la adaptación del éxito literario de Ben Hur. Kalem filmó una adaptación no autorizada sin tener en cuenta los derechos de propiedad intelectual y fue demandado tanto por los editores de la novela original de Lee Wallace, como por los compradores para su versión teatral. Los tribunales decidieron que el término "obra" que históricamente recogían las leyes de propiedad intelectual americanas incluían materiales que no tenían que estar impresos necesariamente, razón por la cual las películas estaban sometidas a esta normativa, tanto para cumplirla como para lograr protección ante posibles infracciones (Bordwell, 1997, p. 143).

\section{OBJETIVOS}

Tal y como se refleja en el título, el objetivo principal del artículo es el estudio de la figura del autor de las obras cinematográficas en el sistema de clásico de Hollywood. Esta acotación no se hace sólo por motivos prácticos, para reducir el tema, y por tanto la envergadura de la investigación, sino que existe una razón más importante: el sistema clásico de producción se considera de forma invariable como el canon, ya sea para seguirlo o para apartarse conscientemente de él. $Y$ sin embargo se conoce mal. Por norma general se repiten una serie de estereotipos, alejados de la realidad, sin profundizar en los procesos de creación cinematográfica de los estudios.

En este artículo se pretende analizar de qué manera ese particular sistema de trabajo en equipo influía en sus creadores, y por qué razones a algunos les llamamos autores y a otros les negamos esa condición. En este sentido se presta especial atención a la figura del productor, puesto que es una profesión que ha sido denostada a lo largo de la historia, pero que merece el máximo reconocimiento. En la tradición anglosajona sí han gozado de cierto prestigio, aunque más bien asociado a la idea de emprendimiento industrial, no artístico. Es decir, como la persona que convoca a un grupo de talentos alrededor de un proyecto, y se ocupa de organizarles y administrar las finanzas. En la mejor aplicación de la doctrina capitalista, los productores de éxito eran los que más dinero obtenían de sus productos, y por eso abundan las historias en las que, con ese objetivo prioritario, desprecian y son despreciados por el resto de creadores cinematográficos, así como por los críticos, y en general por la tradición más intelectual. Aunque pueda haber excepciones que sí se correspondan con esa mala reputación, los productores no solían ser esos demonios de opereta, sino personas muy inteligentes que intentaban sacar adelante las mejores películas que eran capaces dentro del límite del presupuesto, es decir, más o menos lo mismo que el resto de autores en su campo.

También se analizan otras figuras como el montador o el director de fotografía para comprobar hasta qué punto deberían ser tenidas en cuenta como autores. De hecho, uno de los objetivos del artículo es precisamente indagar en el significado de la expresión arte colectivo, un concepto habitual, incluso persistente, pero mal resuelto. En esa línea tampoco se pierde la atención de algunos profesionales directamente ignorados como el supervisor de montaje, que ejercieron una gran

Revista de Comunicación de la SEECI. 15 julio, 2019 / 15 noviembre, 2019, no 49, 39-57 
influencia sobre el acabado final de las películas. Su contribución a la gramática cinematográfica sigue olvidada, pero una aproximación científica a la autoría fílmica debe contar con todos los elementos que han influido en la creación, tanto para bien como para mal.

Por último, no se olvida al guionista o al director, ya que aunque existe un enorme cuerpo teórico sobre su labor, en general se ha hecho desde una perspectiva romántica, poniendo el foco sobre los aspectos más legendarios de su cometido, en lugar de encuadrar su responsabilidad desde un punto de vista pragmático.

\section{METODOLOGÍA}

El propio concepto de cine clásico es una noción que ha ido cambiando su esencia. Unos teóricos lo limitan al periodo circunscrito al Hollywood de los años 30 y 40, mientras que otros incluyen los 50, y hasta más allá. En este estudio se pone el énfasis en el sistema de trabajo de los estudios, y por tanto su pervivencia es lo que marca la frontera de la etapa en cuestión. En el momento en el que el proceso cambia, y las producciones independientes empiezan a ser la norma, en lugar de la excepción, entonces una nueva dinámica comienza a dominar las relaciones de autoría de los creadores. No es que se produzca una revolución entre los cineastas, pero sí que el panorama se va modificando, debido también en parte a la irrupción de la concepción del director como el autor indiscutible, propugnado por los teóricos de la Nouvelle Vague.

Este asunto de la acotación temporal es relevante puesto que limita el acceso a las fuentes originales, y por tanto influye en la metodología. Por supuesto aún ha sido factible el análisis de los films de ese periodo, lo que ha resultado útil para esta investigación, pero lo que no es posible es hablar directamente con los autores, puesto que la mayoría ya han fallecido. La búsqueda de información sobre sus métodos de trabajo, las distintas responsabilidades de cada profesión, o incluso de cada escalón laboral en un determinado ámbito se ha hecho gracias a las declaraciones de los profesionales de entonces plasmadas en estudios anteriores (en libros, revistas o documentales), tal y como queda reflejado en el apartado de bibliografía.

Sin embargo, aunque también se ha acudido a algunos manuales de referencia, o algunas obras académicas clásicas, nuestro enfoque sobre este periodo es distinto al habitual. En general se suele poner la lupa sobre los productos terminados, las obras cinematográficas, y las múltiples interpretaciones que pueden hacerse de su contenido. $\mathrm{O}$ bien se estudia a los artistas escudriñando hasta el último detalle de su biografía. En cambio, aquí el objetivo es el examen de los oficios, para averiguar cuál era el sistema estándar de creación que, aunque no es radicalmente distinto al actual, sí presenta ciertas peculiaridades frecuentemente ignoradas, y que ayudan a entender mejor el concepto de autoría tanto del pasado como del presente.

Por esa razón, para indagar más profundamente cuáles eran los métodos preferidos por los trabajadores, también se ha acudido a otro tipo de publicaciones 
más técnicas como las revistas profesionales, buscando especialmente las entrevistas a los especialistas, como directores de fotografía, guionistas, directores, productores... En último punto es necesario mencionar la experiencia laboral previa como montadores cinematográficos de los investigadores de este artículo. Aunque se trata de un escrito científico, todo ese conocimiento anterior, esa sabiduría profesional adquirida tras años de esfuerzo, se pone al servicio de un punto de vista estrictamente académico, y que sin duda ayuda a solventar ciertas lagunas que no se aprenden de ninguna otra forma.

\section{DISCUSIÓN}

\subsection{La autoría colectiva en el cine}

La noción de autoría colectiva es un concepto difícil de abordar. En realidad, la propia definición de autoría, incluso cuando nos referimos a un artista aislado, es una idea más bien moderna, derivada y modificada a lo largo de la historia por las sucesivas visiones sobre el Arte que trajeron consigo el Renacimiento, el Romanticismo o los movimientos contemporáneos. Pero ese concepto, complicado en sí mismo, se hace aún más complejo si se trata de obras en las que no hay un único responsable, sino varias personas (muchas o pocas, eso es indiferente), que colaboran entre sí hasta llegar a un resultado común. Además, las repercusiones que tiene otorgar la condición de autor a unos u otros no son puramente intelectuales, de la clase con la que gozarían los críticos artísticos, sino que tiene consecuencias directas en el terreno económico, moral y penal.

Tal y como explica Elisa Gutiérrez, la legislación sobre la materia de derechos de autor presenta dos tendencias según la tradición jurídica de los países anglosajones y los países de derecho continental:

En los primeros, los derechos se otorgaban a las personas, físicas o jurídicas que asumieran la iniciativa y responsabilidad del film, lo que encaja con la definición de la figura del productor (...). A este sistema se le denominó "copyright". Los países continentales se decantaron por el sistema de "derechos de autor", prefiriendo otorgar la autoría a determinadas personas que hubieran realizado contribuciones artísticas y/o literarias a la obra resultante. (Gutiérrez García, 2018, p. 8).

Concretamente en el ordenamiento español se ha considerado que los autores de una obra audiovisual eran el guionista, el director y el músico. Desde luego es difícil aceptar que el legislador pueda decretar quiénes son los autores de una obra de arte por encima de lo que piensen los propios creadores, aunque es una constante que las leyes van con retraso respecto a la realidad social que intentan regular. Claro que esta crítica es extensiva a los artículos científicos, como éste, que se empeñan en desentrañar un mundo curiosamente esquivo, que siempre está un paso más allá.

La consideración de autor, en el significado que otorga la ley, tiene un sentido práctico: se les concede un derecho moral y patrimonial sobre el producto 
audiovisual. Es decir, que aparte de su sueldo, y en concepto de derechos de autor, percibirán un pequeño porcentaje de la recaudación de la taquilla ${ }^{3}$. En general, no se trata de una gran suma, aunque en algunos casos en los que se alcanza el éxito, la cifra sube proporcionalmente. Este porcentaje es distinto e independiente de que los autores negocien una participación en los beneficios, algo que en el cine clásico sólo estaba reservado a apenas un puñado de nombres en toda la historia, pues hasta los actores más famosos estaban incorporados permanentemente a un estudio que únicamente les ofrecía un sueldo periódico tanto si rodaban como si no.

En la actualidad, el derecho moral además les proporciona control sobre su obra, como impedir su modificación sin permiso, o el alcance de su divulgación. Normalmente los contratos tienen previstas estas circunstancias, aunque como el derecho moral es irrenunciable, podría darse el caso de que un guionista insatisfecho con el resultado (por ejemplo, el escritor de la novela original, que es el dueño del argumento), impidiese la comercialización de una película ya terminada ${ }^{4}$. El productor podría pedir una fuerte indemnización por los daños y perjuicios, pero le sería difícil oponerse a ello.

El legislador español, y en general el europeo, elige una lista concreta en la que sólo se encuentran el director, el músico y el guionista, y ahora también incluye al director de fotografía. Es evidente que estos son puestos de una gran responsabilidad en un film, y por tanto no hay nada que objetar. Es decir, está claro que el guionista merece ser considerado autor de las películas que escribe, lo mismo que el director o el músico. Sin embargo, es legítimo preguntarse por qué estas personas y no otras. Desde hace ya tiempo hemos intentado demostrar a través de varios artículos, que también hay otros trabajadores cinematográficos, como el director artístico o el montador, que son igualmente esenciales para el cine, y que en determinados casos incluso se constituyen en su principal fuerza creadora, desde los films creados en la etapa dorada de Hollywood hasta los más recientes del panorama nacional.

La pregunta fundamental que se plantea es cuál es la esencia del autor, o dicho de otra forma ¿si una persona desarrolla un trabajo en una obra de arte, se transforma automáticamente en autor? Cuando las obras son la responsabilidad de un único individuo, como en literatura o pintura, no suele haber debate. Sin embargo, el caso del cine es bien distinto, porque se trata de un arte colectivo. Aunque es habitual que haya una figura central que coordina o que dirige el resto de aportaciones, la clave es que el resultado final proviene precisamente de la colaboración. No es una mera suma de voluntades que acumulan su fuerza para levantar un proyecto, sino que se produce una interacción, una influencia mutua entre ellas que provoca resultados muy dispares.

\footnotetext{
${ }^{3}$ En concreto el $1,55 \%$, que a su vez se divide a partes iguales entre los autores.

${ }^{4}$ Durante años se rumoreó que Patricia Highsmith, insatisfecha con la versión de El amigo americano (Der amerikanische Freund, 1977), que Wim Wenders realizó sobre su novela El juego de Ripley, había impedido su reestreno en salas.
} 
Al final del proceso es imposible saber quién fue el responsable de cada idea, no sólo por falta de memoria, sino más bien porque desde la idea original hasta la que queda en la pantalla, la interpretación personal de cada artista va puliendo, o contradiciendo, la del anterior. Un ejemplo de ello lo encontramos en el cine clásico: Según han narrado varios autores, la frase final que Rick le decía al capitán Renault en Casablanca (Michael Curtiz, 1942), "Louis, presiento que éste es el comienzo de una hermosa amistad", fue escrita en realidad por el productor Hal B. Wallis (Ros, 2017, p. 38). Más tarde, ante el gran éxito, tanto los hermanos Epstein como Koch, reivindicaron su papel predominante en la redacción de la obra, incluido este cierre clave.

En la Ley de Propiedad Intelectual de nuestro país existe una definición valiosa que recogemos aquí:

[Una obra colectiva] está constituida por la reunión de aportaciones de diferentes autores cuya contribución personal se funde en una creación única y autónoma, para la cual haya sido concebida sin que sea posible atribuir separadamente a cualquiera de ellos un derecho sobre el conjunto de la obra realizada. ${ }^{5}$

Estamos plenamente de acuerdo con ella, pero eso no resuelve el problema que ya se había anunciado para las obras cinematográficas. Se reconoce su carácter colectivo, pero se restringe la condición de autor a una pequeña lista cerrada. Así que la pregunta sigue en pie, ¿por qué el director, el guionista o el músico? ¿Por qué se incluyó con posterioridad al director de fotografía? ¿Tanta diferencia hay entre el artístico trabajo de unos y las rutinas profesionales del resto del equipo? Para ofrecer una explicación razonable hay que acudir a la tradición. Estas profesiones ya contaban con grupos organizados que se ocupaban de defender sus derechos de autor con anterioridad a la llegada del cine. No hacen falta muchos argumentos para esgrimir que si al escritor o al músico se les considera autores cuando trabajan solos, se les siga tratando igual cuando lo hacen juntos. En cambio la figura del director ha seguido otra trayectoria.

\subsection{El papel del director frente al productor creativo}

En realidad, la reivindicación de la figura del director/autor no llega hasta la Nueva Ola francesa. Antes de ese momento, ningún director se hubiera llamado a sí mismo autor, lo que no significa que subestimaran su propio valor, o que no pensaran en el cine como una manifestación artística. Pero su papel, aunque era fundamental, no dejaba de ser un eslabón en la cadena de los estudios. En Hollywood, su labor se restringía al rodaje, y con menor libertad de acción que en la actualidad. Estamos acostumbrados a pensar en realizadores que controlan casi todos los aspectos de un film desde el comienzo hasta el final, pero en la época dorada del cine, quien ejercía un auténtico control creativo sobre todos los aspectos de la película eran los

\footnotetext{
${ }^{5}$ España. Real Decreto Legislativo 1/1996, de 12 de abril, por el que se aprueba el Texto Refundido de la Ley de Propiedad Intelectual. Artículo 8. Obra colectiva.
} 
productores. Es casi un problema de nomenclatura, porque se podría decir que el productor de entonces era el equivalente al director de ahora, puesto que tenía la última palabra en las decisiones creativas, con la diferencia de que el productor delegaba en alguien para la supervisión del rodaje. La prueba definitiva es que la mayoría de los directores no acudían a la sala de montaje, sino que era el propio montador, en soledad o colaborando con el productor, quien decidía la estructura definitiva del largometraje. Eso sí, en el sistema clásico había que tener en cuenta también a la figura del supervisor de montaje, o a los ejecutivos de los estudios, que podían ejercer una gran influencia: si se hubiera podido decir que los directores ejercía un papel de liderazgo en los equipos, este habría estado limitado a lo que Vidal Ramentól y Fuertes Camacho (2012) llaman un liderazgo participativo.

En aquella época no existía la absurda expresión, en la que, al principio de los títulos de crédito, se dice "una película de [el nombre del director]". Ahora es tan familiar que se acepta sin cuestionarla. Pero no es un latiguillo inocente. Con ella se entiende que el director es el verdadero autor del film, y por eso deja su firma. Aunque a regañadientes se reconozca la ayuda de otros participantes, es una admisión limitada, lo justo para no arrebatarle el protagonismo absoluto.

Es pertinente resaltar que cuando en el mundo del Teatro se dice "una obra de", nadie se refiere al director de la puesta en escena, sino al escritor del texto. El autor es el dramaturgo creador del libreto, sin ninguna discusión. Es más, el director de una obra teatral, por muy famoso que sea, ni siquiera cobra derechos de autor. Únicamente el músico se lleva un pequeño porcentaje, ya que casi todo el importe se destina al escritor.

André Bazin y sus discípulos defendían que "Un autor es aquel director que logra a través de un sello estilístico único en la forma que usa el lenguaje fílmico, expresar su visión del mundo, su ideología, y sus obsesiones" (Gutiérrez Correa, 2014, p. 7). Destacaron dentro del cine clásico de Hollywood a Alfred Hitchcock, Orson Welles, Howard Hawks y William Wyler en un principio, y fueron ampliando la lista en sus escritos de Cahiers du Cinéma.

El americano Andrew Sarris, crítico de cine en la revista Film Culture se hizo eco en su país de las ideas de los críticos franceses. Algunas voces como la de Pauline Kael, de la conocida revista New Yorker se opusieron abiertamente, argumentando que "en la mayoría de las películas, el director no es la cabeza del film, que es el producto de la labor creativa de varias personas desde sus diferentes oficios" (Gutiérrez Correa, 2014, p. 16).

Estas ideas alternativas de la Nueva Ola, que en principio estaban circunscritas a un grupo local, muy teórico, se han diseminado por el resto del mundo, marcando tan profundamente la concepción del director moderno, hasta en Estados Unidos, que ahora parece lo natural o lo único posible. Siempre habrá una persona que lleve la iniciativa artística de un proyecto, y el hecho de que sea el productor o el director tiene tanto ventajas como inconvenientes. Es importante no olvidar que existen otras alternativas al método vigente hoy en día. 
Nadie dudaría en considerar a John Ford como un autor de leyenda, y sin embargo, al acabar de rodar se iba de vacaciones. El único consejo que daba al montador es que no le fastidiara la película. No se trataba de un comportamiento excéntrico, era lo habitual. Otros realizadores lo que hacían era enganchar un rodaje con el siguiente, de sucesivos proyectos, que no les dejaban tiempo para sentarse con el montador. Por ejemplo, John Huston seguía un modelo similar, y aun así sigue siendo un referente mundial. En el magnífico libro Picture, Rodando con Huston, la periodista Lillian Ross describió el doloroso alumbramiento de la película $L a R o j a$ Insignia del Valor (The Red Badge of Courage, 1974). Huston, aparece en el título y en la foto de portada, pero el texto, imprescindible para entender el sistema de estudios del Hollywood clásico, desvela que era el productor, Gottfried Reinhardt, quien trabajó con Benny Lewis en el montaje del film (Ross, 1986).

Por supuesto existían excepciones en las que ciertos directores supervisaban todo el proceso, como Alfred Hitchcock o Charles Chaplin, pero destacaban precisamente por eso. Chaplin era su propio productor gracias al estudio que creó, United Artists, junto a otros grandes de Hollywood, Douglas Fairbanks, Mary Pickford y D. W. Griffith, que durante un tiempo se mantuvo como productora independiente con una suerte desigual (Gomery, 1986, p. 209). Al principio de su etapa americana, Hitchcock también tuvo problemas para poder asistir a montaje, hasta que pudo acumular el suficiente prestigio e independencia para llegar a productor. Éste era el camino natural de aquellos creadores que querían tener el máximo control creativo.

Después de estas precisiones sobre el productor creativo, se entienden mucho mejor las razones del derecho anglosajón para designar a éste como el depositario del copyright. En nuestro país parece una decisión arbitraria, pero el hecho de que tenga mala fama no le resta capacidad artística. De la misma forma también se comprende por qué los premios Oscar de la Academia de Hollywood a la "Mejor Película" los recoge el productor de la misma, porque se considera el creador, el auténtico responsable de la obra en su conjunto.

\subsection{Los artífices de historias}

En los primeros años del cine de Hollywood ni siquiera existía lo que hoy se entiende como "guion". Tan sólo una ligera idea de la trama era suficiente para comenzar el rodaje. Progresivamente se fueron dando cuenta de que el agrupar los planos que sucedían en un mismo enclave, en lugar de seguir el orden natural de la historia, hacía más rápida y eficiente esta fase. Y con la imposición de los exhibidores en un momento dado de una duración estándar, se vieron obligados a dedicar más tiempo a preparar los guiones para que la narración conservara una estructura equilibrada de principio, nudo y desenlace heredada de su antecesor literario.

Nuevas exigencias de aumentar la calidad y el metraje de las películas, fueron haciendo necesaria una mejor planificación y el guion detallado se convirtió en una herramienta indispensable para calcular los costes del producto final, y favorecer la eficiencia del trabajo del equipo. Los realizadores perdieron antiguas funciones con el nuevo sistema y pasaron a convertirse en expertos en la dirección de actores y en 
coordinar a los distintos jefes técnicos durante el rodaje, pero bajo la supervisión del productor.

Más adelante, en numerosos estudios se adoptó la fórmula del "guion de continuidad" en el que se describían con detalle las acciones que se llevarían a cabo en la puesta en escena. Si lo comparamos con el modelo que se utiliza en la actualidad, estaría a medio camino entre un guion y un parte técnico (de cámara, de script, y de laboratorio) ya que recogía anotaciones sobre metraje rodado, efectos a realizar, instrucciones sobre tintados y notas para los montadores.

Y frente a este modelo estricto de operar, existían otros métodos como el de Griffith, también compartido por Chaplin, que empleaba para rodar un guion apenas esbozado. Según narra Bordwell (1997, p. 153), su montador recordaba cómo procedía el cineasta mediante largos ensayos, rodando luego planos generales, y después de las primeras pruebas, decidiendo dónde quería los primeros planos. Podía permitirse ser tan lento como quisiera ya que no era pagado conforme al tiempo invertido sino a los beneficios, y tampoco tenía una fecha límite de distribución; ambos privilegios conseguidos en parte gracias a sus éxitos de taquilla. Según se explica en el mismo párrafo, Cecil B. De Mille también se alejaba de las prácticas dominantes en la industria. Para lograr una mayor intensidad dramática de los actores, rodaba en el orden natural de la historia, y colocaba varias cámaras para lograr en una sola toma todos los planos. Con este sistema se conseguía una gran continuidad y se favorecía a los intérpretes pero conllevaba cierta complicación a la hora de iluminar los primeros planos y requería un gran número de operadores, lo que podría haber resultado costoso. Sin embargo, la reducción del tiempo de rodaje y la calidad del resultado final, convencían a la empresa productora en este caso.

Conforme fue aumentando la complejidad de los films, los departamentos de escritura y revisión de guiones, se fueron haciendo cada vez más numerosos. Era una práctica habitual el poner a trabajar a diversos profesionales en el tratamiento de un tema, dejando al margen en ocasiones a la cabeza visible, que solía ser el escritor célebre contratado por el estudio para dar fama al proyecto. Según Nacache (1995, p. 66), la Screenwriters Guild (Gremio de Guionistas) tuvo que resolver más de una vez un caso de paternidad para responder a "las reivindicaciones de algunos guionistas excluidos a lo largo de un procedimiento de escritura debidamente estratificado". Louis B. Mayer defendía que la función de las películas era la de entretener, así que cuando un guionista se quejaba de que habían modificado su trabajo, siempre respondía: "el libro más importante de todos los tiempos lo escribió un comité. Era la biblia". (Ross, 1991, p. 145).

El primer crédito que apareció de un guionista (del jefe de guionistas, no así de los técnicos de continuidad) fue utilizado en 1912 por Edison (Bordwell, 1997, p. 349) con el propósito de animar a otros escritores a enviar sus historias y reducir el riesgo de plagio. El problema surgía cuando las empresas se negaban a enumerar en las películas a todos los participantes en el texto, que podían llegar a ser una decena. No había en los autores tanto una búsqueda de reconocimiento por parte del público sino por parte de la industria porque el ser autor de un film de prestigio, permitía 
mejores condiciones laborales, mayores honorarios y la posibilidad de conseguir nuevos proyectos. En este sentido, la Academy of Motion Picture Art \& Sciences, aparte de organizar los premios anuales de las distintas categorías a "Mejor película" o "Mejor Fotografía", publicaba un boletín mensual en el que detallaba todos los participantes en el guion de un título concreto, para distribuirlo entre los distintos directivos de las diferentes compañías.

Muchos novelistas famosos, como Raymond Chandler, Scott Fitzgerald, o Dos Passos, fueron llamados por los estudios para la adaptación de sus novelas, aunque su relación con los productores partía de un recelo mutuo, que por lo general derivaba en interminables discusiones. Otros, en cambio, como la dramaturga Lilian Hellman, supo adaptarse al oficio de guionista y cambió su rechazo inicial por un gran entusiasmo hacia las múltiples opciones que le proporcionaba el nuevo medio.

Sin embargo, eran más frecuentes las quejas por la poca atención que se le prestaba a su talento, ya que los productores solían pedir la revisión de sus aportaciones, por parte de otros profesionales asalariados del estudio, más pragmáticos y con menores pretensiones intelectuales. Según relatan estudiosos como Enric Ros (2017, p. 38), William Faulkner apenas aportó unas líneas al guion de Tierra de faraones (Land of the Pharaohs, Howard Hawks, 1955), después de que la producción le costeara un viaje a Egipto de cuatro meses. La imposición de la disciplina de alto rendimiento y cumplimiento de horarios de los estudios tampoco favorecía la inspiración de este tipo de artistas. Raymond Chandler describió su colaboración con Billy Wilder en Perdición (Double Indemnity, 1944) como "una experiencia asesina que probablemente ha acortado mi vida, pero aprendí cómo se escribe un guion, tanto como soy capaz de aprender, lo que no es mucho" (García, 1999). Wilder pensaba que podría aportar valiosos elementos a la historia: "Se interesaba como yo por la atmósfera de una ciudad, de una situación, de una persona. Tenía oído para los matices del "slang". Además, no sólo era un autor que podía describir de un modo maravilloso, sino que también podía escribir diálogos". (García, 1999).

Sin embargo, pronto fue consciente de su difícil carácter y de su manifiesto desdén hacia el oficio del guionista, como recuerda Cecilia García.

Quizás el novelista, como tantos otros provenientes de la literatura, se sentía inseguro a la hora de cómo se debía escribir para un film, según revelan las cartas enviadas a su amigo, el actor Charles Morton:

No hay disponible un cuerpo de bibliografía de guiones, porque estos pertenecen a los estudios, no a los autores, y los estudios no los mostrarán. Por ejemplo, yo traté de pedir prestado de la Warner el guion de El Halcón Maltés; no me lo dieron. Todo lo que puede hacer el escritor es ver las películas. (...) No puede hacer un estudio detallado y una reconstrucción de los problemas. (Chandler, 2013).

Denunciaba a su vez las contradicciones del sistema: "El guion tal como existe es el resultado de una enconada y prolongada batalla entre el escritor (o los escritores) 
y la gente cuyo objetivo es explotar su talento sin darle la libertad de usar ese talento"(Chandler, 2013). A pesar de esto, terminaba alabando en la misma carta la generosidad de las empresas audiovisuales que al contrario que su editor, cuando conseguía un gran éxito, negociaban con él de nuevo: " $Y$ cuando escribo algo que da ganancias, entonces rompe mi contrato y redacta uno mejor. No puedo despreciar a una industria que hace eso"(Chandler, 2013).

\subsection{Las distintas disciplinas}

Las exigencias de películas de mayor calidad, con la capacidad de ser verosímiles, de emocionar e impresionar al espectador, animaron a las empresas a contratar a los mejores profesionales del mundo del teatro, la música, la moda... Numerosos artistas de otras disciplinas como la pintura o la arquitectura se convirtieron en consejeros expertos de las diferentes categorías cinematográficas. Esta llegada masiva aumentó la especialización y favoreció el perfeccionamiento de las técnicas en todos los campos, dando lugar a nuevos puestos.

La figura de la script (que hasta hace relativamente pocos años seguía dominada por las mujeres) se hizo imprescindible a la hora de prestar la atención requerida al raccord, y para servir de puente entre el rodaje y la sala de montaje. Se ocupaba de supervisar el respeto a la continuidad de los planos rodados en momentos diferentes que luego en pantalla habían de aparecer seguidos. Y a su vez, escribía anotaciones que pudieran servir de ayuda para de organizar el material. Es decir, como hoy en día.

Se ampliaron de modo progresivo las responsabilidades del ayudante de dirección que debía agrupar los planos que iban a ser rodados cada jornada, y llevar a cabo una supervisión de la iluminación del plató, los decorados, el vestuario y las localizaciones de exteriores. Liberaba de esta manera al director de las tareas previas al rodaje y establecía una conexión entre el director, la producción y el personal del set.

Uno de los primeros directores artísticos que comenzaron como aprendices en estudios cinematográficos fue Anton Grot, nominado a los premios Oscar por El Halcón del Mar (The Sea Hawk, Michael Curtiz, 1940). Con el apoyo del personal de investigación evitaba anacronismos en los decorados, pero además de la decoración, debía poseer conocimientos técnicos sobre construcción de estructuras, las características del celuloide y la respuesta de los diferentes objetivos. Inicialmente diseñó sets para el productor Sigmund Lubin a la manera tradicional pero pronto desarrollaría métodos revolucionarios. Según el cámara Arthur Miller, Grot hacía dibujos a lápiz cuidadosamente sombreados que resultaban especialmente útiles a la hora de iluminar. Añade que ideó una "tabla decreciente", usando distintas lentes y marcando en fotografías la forma en la que la profundidad de campo retrocedía al fondo. Este procedimiento estimuló sus experimentos posteriores con una perspectiva falsa, permitiendo efectos espaciales espectaculares a costos muy reducidos (Ramírez, 2004). Era también común el empleo de maquetas en miniatura de los decorados que ayudaban a planificar previamente los ángulos de cámara, la iluminación y la posición de los actores. 


\subsection{La colaboración en el rodaje}

En cualquier película resulta necesaria la implicación de todos los profesionales que participan en ella, aun actualmente, y en la enorme maquinaria del cine de Hollywood, desde los trabajadores de escalas inferiores hasta los directivos más altos de la producción contribuían al desarrollo de cada proyecto, en mayor o menor medida.

El director de fotografía Lucien Ballard, responsable del film Atraco perfecto (The Killing, Stanley Kubrick, 1956) dijo en una ocasión: "Otra cosa que aprendes es que el operador de cámara no puede hacer una película tal y como quiere porque no es quien manda. Se trata de una colaboración entre el director, el director artístico y el operador"(Bordwell, 1997, p. 156).

Conviene destacar también en este punto a los técnicos de efectos especiales. En el caso de Ciudadano Kane (Citizen Kane, Orson Welles, 1941) fueron responsables junto con el director de fotografía Gregg Toland de los planos más innovadores de la obra.

Los títulos de mayor presupuesto como las superproducciones, se convertían según la investigadora Jacqueline Nacache en un "terreno ambiguo, lugar de elecciones y contradicciones, donde el gigantismo puede ampliar la voz de un artista o hundirla por completo" (1995, p. 81). Por eso, afirmaba que la figura dominante de este tipo de largometrajes solía ser la del productor, ofreciendo como ejemplo paradigmático Lo que el viento se llevó (Gone with the wind, 1939), con tres directores, George Cukor, Sam Wood (ambos excluidos de los títulos de crédito) y Victor Fleming, pero "un solo verdadero responsable: David O 'Selznick" (Nacache, 1995, p. 81).

Dependiendo de la compañía en la que trabajaran, y también de la personalidad del productor que se ocupara de la coordinación, los realizadores gozaban de mayor o menor margen de maniobra. Los cineastas se valían de su reconocida fama para lograr todo el control posible, al menos en la fase de rodaje.

El director Vincent Sherman, autor de $A$ través de la noche (All Through the Night, 1942) recordaba:

Después de haber visto muchas de las películas de John Ford, puedo imaginarme que hace una buena parte del montaje con la cámara. En Warner Brothers no podíamos hacerlo. Si lo hubiéramos hecho, nos habríamos metido en problemas de inmediato. Sabíamos que debíamos cubrir una escena desde diferentes ángulos para que hubiera distintas opciones, de modo que Wallis y Warner pudieran elegir qué querían. (Bordwell, 1997, p. 367).

Minnelli, que trabajó en la unidad de producción de la MGM junto a Stanley Donen y Gene Kelly, decía en sus memorias que gracias al productor Arthur Freed la comedia musical se desarrolló de aquel modo: "Él es el que dio a todos los creadores la mayor libertad posible y ésa es la marca de confianza indispensable para toda creación"(Minnelli, 1975, p. 123). 


\subsection{La elección del corte}

El montaje final, en la mayoría de los casos, no era supervisado por el director, como se concibe hoy en día, sino que era el productor el que acompañaba al montador en esta fase de creación de la película. El realizador solía limitarse al control del proceso de rodaje. Sólo algunos cineastas le planteaban al estudio esta posibilidad, siempre y cuando gozaran de un alto estatus que les permitiera negociar sus condiciones. En los años veinte, Lubitsch negoció con Warner Bros tener el control sobre el corte definitivo además de la última palabra acerca del reparto y el argumento (Bordwell, 1997, p. 154). Como apuntábamos en un párrafo anterior, Hitchcock logró mediante un plan deliberado que fuera requerido en la sala de montaje, ya que rodó de tal manera el material de Rebeca (Rebecca, 1940), su primer título en Estados Unidos, que el editor se vio obligado a recurrir a él para darle sentido.

La figura del supervisor de montaje también jugaba un papel importante en este proceso ya que actuaba en nombre del estudio, coordinando a los distintos profesionales en una misma dirección. Margaret Booth fue una de las más destacadas de la profesión. Muchos opinaban que era un lenguaje fílmico muy estricto también en términos de montaje, que los editores sabían que no debían romper. Se decía de Booth que era la más temida e implacable de la MGM pero, por otro lado, según los testimonios sobre lo que solía indicarles a los montadores, no parecía ser tan inflexible en el estilo ya que primaba otras cuestiones sobre el raccord: "Si crees que hay que cortar en un punto tanto si cuadra como si no, corta. Se corta buscando la emoción y se consigue mucho actuando asf" (Apple, 2006).

El editor Adrienne Fazan, responsable del montaje de Cantando bajo la lluvia (Singin' in the Rain, Stanley Donen y Gene Kelly, 1952) relataba que la severa supervisora esperaba de él que utilizara primeros planos en un film de Vincente Minnelli. Sin embargo no era posible porque había decidido no rodarlos. El director planeó hacer largos planos generales con movimientos de cámara a propósito para que no hicieran cambios en la sala de montaje. Entonces en el estudio, ampliaron estos fotogramas reencuadrando, para obtener de este modo los primeros planos inexistentes en un principio (Bordwell, 1997, p. 368).

Según Nacache, en el cine clásico, en especial en el estudio de la Warner Bros., se desarrolló un estilo de montaje rápido, es decir, con abundancia de elipsis y planos sin excesiva duración, ya que permitía "contar historias complejas, incluso oscuras, sin producir traumas en el espectador" (Nacache, 1995, p. 33). Se decía que Jack Warner obligaba a cortar los fragmentos que mostraban un personaje yendo de un lugar a otro por resultar inútil para la narración y únicamente "desgastaban suela de zapato"(Coursodon, 1991).

Estas ideas innovadoras no se repetían en todos los films de la industria, puesto que muchos directores, fundamentalmente los de origen europeo, como Stroheim o Sternberg, se resistían a acortar los planos, porque constituía para ellos una traición a su particular modo de expresión. Welles, dentro de sus modernas propuestas, 
tampoco propugnaba fugacidad en los planos. De hecho, en varias de sus obras, como en El cuarto mandamiento (The Magnificent Ambersons, 1942), podemos observar cómo fuerza este estilo premeditadamente lento.

A lo largo del período del cine clásico de Hollywood hubo diferentes sistemas de producción que fueron desarrollando ciertas tendencias cíclicas en cuanto a la creación, pero sólo la confluencia de todos los profesionales, especializados en los distintos aspectos necesarios para componer una película, creó un estilo que sigue perdurando hoy en día en la cinematografía mundial.

\section{CONCLUSIONES}

Hay que tener en cuenta la figura del productor. Sin duda, su imagen ha sido criticada y su papel ha originado multitud de detractores. Para muchos existe la creencia errónea de que la misión de un productor consiste únicamente en gestionar los aspectos económicos del film, y dan especial valor a los que permiten al director la máxima autonomía. En efecto a lo largo de la Historia de la Cinematografía se pueden encontrar personas con falta de interés cultural, desconocimiento del medio o simplemente ausencia de talento, pero igualmente es cierto que en contraposición a ellas, numerosos productores han dejado una profunda huella por su participación, debido a su inteligencia, interés y experiencia. Esta circunstancia se da especialmente en la época dorada en Hollywood, con nombres destacados como el de Arthur Freed o David O'Selznick, y se sigue manteniendo en los Estados Unidos hoy en día.

La incorporación de la figura del productor en el conjunto de los autores reconocidos de una obra puede plantear objeciones como sucede con el resto de otras participaciones, entre ellas, por citar algunas, las de los intérpretes, montadores u otros colaboradores como los que participan en el sonido, la decoración... Pero lo cierto es que habría que considerar a todos los que contribuyen con su trabajo, eso sí, cada uno en función de su contribución (Lara, 2006). Por ejemplo, el trabajo del ayudante de dirección es sumamente importante aunque esté bajo las órdenes del director. De hecho, el término de "ayudante", desde su empleo en el cine clásico, no refleja su valor, ya que en realidad se trata del verdadero jefe de rodaje. Y sin embargo su aportación a la autoría es quizá más limitada que en otros oficios.

Tendría que establecerse un baremo que se pudiera incorporar a una ley de propiedad intelectual, en la que no se excluyera a ninguno de los autores, aunque estos se distinguieran proporcionalmente con respecto a su contribución. Desde los inicios del cine sigue sin resolverse esta cuestión y tal vez, en algún momento se conseguirá adaptar a una normativa esta múltiple realidad del concepto de autor.

Es difícil conocer la complejidad que supone la creación de una película. Los espectadores que acuden a las salas reciben los títulos de crédito con resignación y en muchas ocasiones ni siquiera esperan y se marchan antes de concluir la proyección. Una labor pedagógica consistiría en explicar que hay tareas necesarias 
en la realización de una película y que muchos de los oficios, por ejemplo los técnicos de laboratorio, son imprescindibles. Esto no quiere decir que sean autores. Numerosas personas trabajan para conseguir llevar a cabo cada proyecto, desde el responsable del catering a los conductores, pero no todos y cada uno de ellos deben ser considerados artistas. La cuestión sería plantearse si se modificaría la obra final al sustituir a uno por otro, si esto tendría una influencia directa en el resultado.

Walter Murch, uno de los pocos montadores cuyo nombre ha salido del anonimato, considera el Arte Cinematográfico como una actividad esencialmente colectiva, una de las características que marca la diferencia con otras formas de expresión artística (Murch, 2003). Otros opinan lo mismo. No obstante en el mundo audiovisual, se seguirán produciendo cambios todavía impredecibles.

Por ejemplo, el rodaje sufrirá una transformación tan enorme que ni se parecerá a lo que conocemos hoy. También desaparecerán muchos de los oficios que en la actualidad crean la imagen fílmica, y que en el futuro serán sustituidos por unas pocas personas, o quizá una sola, provista de un ordenador. Eso sí, lo fundamental será siempre la inspiración y el talento de los creadores.

Con el paso del tiempo, las posibilidades de la tecnología por un lado y el desarrollo de las generaciones asociadas a ella ["Net generation" (Oblinger y Oblinger, 2005), generación ND (Nacido Digital), generación C -"Creatividad, Contenido, Compartir"- (Búa, 2010), Echo Boomers (OMD, 2012), o, más comúnmente denominada, generación $\mathrm{Y}$ ○ Millennials como concluyen Alonso Mosquera, Gonzálvez Vallés y Muñoz de Luna, (2016)] por otro tal vez haga que se elimine la colaboración, y un solo autor concentre en sí mismo a todo el equipo técnico y artístico, en una labor más individual, semejante a la de un escritor o un pintor. Cabe preguntarse adónde nos llevarán estos cambios, lejos del tradicional lenguaje cinematográfico, creado y refinado a lo largo de la icónica etapa clásica de Hollywood.

\section{REFERENCIAS}

Alonso Mosquera, M. H., Gonzálvez Vallés, J. E. y Muñoz de Luna, A. B. (2016). Ventajas e inconvenientes del uso de dispositivos electrónicos en el aula: percepción de los estudiantes de grados en comunicación. Revista de Comunicación de la SEECI, XX(41), 136-154. doi: http://dx.doi.org/10.15198/seeci.2016.41

Apple, W. (Directora). (2006). The cutting edge: The magic of movie editing. [Película]. EE.UU.: Starz Encore Entertainment.

Bordwell, D.; Staiger, J.; y Thompson, K. (1997). El cine clásico de Hollywood. Estilo cinematográfico y modo de producción hasta 1960. Barcelona: Paidós.

Chandler, R. (2013). A mis mejores amigos no los he visto nunca: Cartas y ensayos selectos. Barcelona: Debolsillo. 
Coursodon, J. P. (1991). La Warner Bros. París: Centre Pompidou.

Ehrengurg, I. (2008). La Fábrica de sueños. Santa Cruz de Tenerife: Editorial Melusina.

García, C. (28 de Febrero de 1999). Temblad, corruptos del mundo, El Cultural. Recuperado de: http://www.elcultural.com/revista/cine/Temblad-corruptos-delmundo/13585

Gomery, D. (1986). Hollywood: El sistema de los estudios. Madrid: Verdoux.

Gubern, R. (1998). Historia del cine. Barcelona: Editorial Lumen.

Gutiérrez Correa, M. (2014). El cine de autor del cine moderno al cine posmoderno, Razón y Palabra, 18, 87. Recuperado de: http://www.redalyc.org/articulo.oa ?id $=199531505030$

Gutiérrez García, E. (2018). La autoría de la obra audiovisual. (Pendiente de publicación).

Lara, A. (2005). El cine ha muerto, larga vida al cine. Pasado, presente y futuro de la Postproducción. Madrid: T\&B Editores.

Lara, A. (2007). La especificidad de las obras audiovisuales. E-Prints Complutense.

Lara, M. (2016). Fernando Colomo. Su cine desde dentro. Madrid: Ocho y Medio.

Minnelli, V. (1975). I Remember It Well. Sydney: Angus and Robertson.

Murch, W. (2003). En el momento del parpadeo, Madrid: Ocho y Medio.

Nacache, J. (1995). El cine de Hollywood. Madrid: Acento Editorial.

Oblinger, D. G. y Oblinger, J. L. (2005): Introduction. Educating the net generation. Disponible en http://www.educause.edu/Resources/EducatingtheNetGeneration/Introduction/60 $\underline{59}$

OMD (2012): Millenials. Disponible en http://www.omd.es/DigitalCenter/Onmedia/Agosto12/3.html

Ramírez, J. A. (2004). Architecture for the Screen: A Critical Study of Set Design in Hollywood's Golden Age. McFarland.

Ros, E. (2017). Escritores en Hollywood, historia de un desencanto, Qué leer, 234, 38-43. Recuperado de: http://www.que-leer.com/2017/11/07/escritores-enhollywood-historia-de-un-desencanto/ 
Ross, L. (1991). Picture: Rodando con Huston. Madrid: Plot Ediciones.

\section{AUTORES:}

\section{María Lara}

Ejerce como docente de Comunicación Audiovisual desde 2003. Ha impartido clases en la URJC y la Nebrija. Actualmente es profesora en el Departamento de Teorías y Análisis de la Comunicación de la Universidad Complutense con las asignaturas de "Edición y Postproducción" y "Arte Visual". A su vez trabaja como montadora de cine desde 1994. Ha editado 12 largometrajes, entre los que destacan las últimas películas de Fernando Colomo, Isla Bonita y La Tribu.

mlara04@ucm.es

Orcid ID: orcid.org/0000-0002-6414-8034

Google Scholar: https://scholar.google.es/citations?user=TxyBkB4AAAAJ\&hl=es

ResearchGate: https://www.researchgate.net/profile/Maria Lara19

Researcher Id: I-6272-2016

Academia.edu: https://ucm.academia.edu/MariaLara

\section{Antonio Lara}

Profesor titular en la Universidad Rey Juan Carlos donde imparte las asignaturas de "Realización cinematográfica y televisiva". Es autor del libro de análisis sobre el pasado, presente y futuro de la postproducción, El cine ha muerto, larga vida al cine. Al tiempo, desde 1994 ha montado 16 películas, entre las que destacan el documental De Salamanca a ninguna parte, de Chema de la Peña y Al Sur de Granada y Rivales, de Fernando Colomo.

antonio.lara@urjc.es

Orcid ID: orcid.org/0000-0002-2158-8646

Google Scholar: https://scholar.google.es/citations?hl=es\&user=t7ZBH5sAAAAJ 